\title{
Clinical practice guidelines - the Sri Lankan perspective
}

\author{
Journal of the Ceylon College of Physicians, 2014, 45, 1-2
}

"What we think, or what we know, or what we believe is, in the end, of little consequence. The only consequence is what we do." - John Ruskin

Our College has given excellent leadership, over five decades, to the field of Clinical Medicine in Sri Lanka that has enabled the sustenance of a vibrant and active discipline. Therefore it is appropriate to review and reflect on issues that require further improvements to our day to day practice, which can be addressed through our College Journal. This is particularly in view of the continued expansion of knowledge and the major developments in technology that impact on the quality of care of our patients. The evolution of new health facilities such as Emergency Medicine and Elderly Care in our country are appropriate to the changing needs of health care services. Such expansions place additional demands on our members; both the general physicians and subspecialists. Therefore we need to re-visit and address the role of clinical practice guidelines (CPGs) that are appropriate to our local setting. CPGs are handy tools for practitioners to make clinical decisions and improve health outcomes. Treatment recommendations have been in circulation for undergraduate / postgraduate training and for specific purposes like immunization schedules, critical management algorithms etc. But in the past decade or more there has been a shift towards formal evidence-based CPGs that are intertwined with a regulatory outlook to ensure patient safety and quality of care. Quality of healthcare is providing the right care, at the right time, by the right person in the right manner, with CPGs observed at clinician level and in policy planning to promote efficient allocation of resources and better care delivery. ${ }^{1}$

Hence, we need to appreciate that the development and adoption of national CPGs should primarily aim at improving our health care quality, safety, and efficiency. Clinical guidelines must aim at affording patients the opportunity of receiving the best evidence based clinical decisions and care, the optimal utilization of available resources and most importantly, the regular review of our clinical services. ${ }^{2}$ However, changing our clinical outlook to an evidence based medicine (EBM) approach by adhering to CPGs have met with some debate in our clinical training and practice over the past decade. This is not unique to Sri Lanka. A review of the impact of national guidelines by the UK National Institute for Health and Clinical Excellence (NICE), reported successes along with many mixed results. ${ }^{3}$ Negative comments on the use of guidelines included issues related to clinicians who viewed them with displeasure because they felt restricted and restrained in the decision making. They felt isolated and became resentful of the inflexibility of hierarchical commands. ${ }^{4}$ Yet another criticism was that individualized patient care was compromised due to relevant issues being overlooked - such as comorbidities, socio-cultural issues and conflicts with professional clinical judgment of the 'experienced' clinician. $^{2}$ Critics of the EBM approach cite the unacceptable outcomes of this approach that led to over diagnosis and over treatment. ${ }^{5}$ Whereas the true intention of the EBM approach was to encourage critical thinking, it is widely observed now as being a "catch phrase" that justifies the term "expert" who is likely to be ensconced in an aura of being unchallenged! The correct EBM approach must focus on the outcomes that truly matter to patients in helping them live longer or better. ${ }^{6}$

However, we need to accept that a standardized approach to clinical care is required and that practice guidelines are in fact required. Therefore, what should be the pragmatic approach to this? Suggested methods of improving implementation of CPGs are by addressing and overcoming the drawbacks. These include continued education, clinical audit, incorporating costing tools and the development of clinical decision supports on the part of guideline developers. But more importantly, the feedback and review by the care givers must be encouraged, who must appreciate that guidelines are developed not to compromise their clinical autonomy but to improve patient care. ${ }^{3}$ The increased recognition world-wide of numerous errors in medical practice has highlighted how the quality and safety of patient care is compromised that requires our urgent attention. ${ }^{7}$ Hence, the adoption of Clinical Practice Guidelines seems a sensible means to minimize error. Nevertheless, the adherence to guide- 
lines by practitioners who require to read through the textual information that includes the rationale for the recommendations and to respond appropriately does not happen uniformly.

Our College was closely involved with the Ministry of Health for this specific purpose since 2005 by developing guidelines with stakeholder participation, with their dissemination through the College in 2007. The Health Sector Development Project of Sri Lanka, in fact, encouraged the development of guidelines by the professional colleges themselves (representative of the main stakeholder among the caregivers), rather than the Ministry of Health (the regulator). They encouraged the participation of clinicians and adopted a more bottoms-up approach. Yet, the utilization and impact of these guidelines was not measured nor formally reviewed, and was indeed a missed opportunity in addressing our approach to the quality and standards of patient care.

This journal issue includes preliminary data that highlights the drawbacks and challenges faced by clinicians who manage ST elevation myocardial infarction in an outstation setting with limited resources, with major restrictions in technological support. The editorial board has hence encouraged the development of pragmatic guidelines that conform to the scientific evidence as well as its application to our local setting. Therefore, we publish in this issue STEMI Management Guidelines, endorsed by the Sri Lanka Heart Association.
We look forward to your critique and comments, active participation in their application and audit, which thereby is expected to snowball into an ethos of quality and safety approach in our day to day clinical practice.

\section{References}

1. Cynthia M Farquhar, Emma W Kofa and Jean R Slutsky. Clinicians' attitudes to clinical practice guidelines: a systematic review. Med J Aust 2002; 177(9): 502-6.

2. Chidgey J, Leng C, Lacey T. Implementing NICE guidance. J R Soc Med 2007; 100: 448-52.

3. Fox J, Patkar V, Chronakis I, Begent R. From practice guidelines to clinical decision support: closing the loop. J R Soc Med 2009: 102: 464-473. DOI 10.1258/ jrsm.2009.090010

4. Croft P, Malmivaara A, Tulder MV. The pros and cons of evidence-based medicine. Spine (Published Ahead of Print) DOI: 10.1097/BRS. 0b013e318223ae4c

5. Des Spence. Editorial: Evidence based medicine is broken. BMJ 2014; 348: 22 doi: http://dx.doi.org/ 10.1136/bmj.g22

6. William Cayley: Evidence based medicine - it's time to be critical http://blogs.bmj.com/bmj/2014/01/07/ william-cayley-evidence-based-medicine-its-time-tobe-critical/

7. Kohn LT, Corrigan JM, Donaldson MS, editors. To err is human: building a safer health system. Washington, DC: National Academy Press, Institute of Medicine; 1999.

\section{Chandrika N Wijeyaratne}

Co-Editor 